\title{
The Influence of Arterial Pressure on Mitral Incompetence in Man*
}

\author{
Anthony D. Jose, R. R. Taylor, $\dagger$ and L. Bernstein $†$ \\ (From the Hallstrom Institute of Cardiology, Royal Prince Alfred Hospital, Sydney, \\ Australia)
}

The pathology of mitral incompetence has been extensively studied during surgery $(1-4)$ and at autopsy $(5,6)$. The incompetence may be caused by an organic valve lesion of several varieties, by dilatation of the mitral annulus, or by both. Annular dilatation leads to a relative deficiency of valve substance, producing incompetence which can be termed functional, to distinguish it from that caused by organic lesions. Often these two exist together. but annular dilatation is found alone in up to a quarter of patients undergoing corrective surgery (2). In these patients the primary disease appears to be myocardial rather than valvular (7).

The regurgitant flow in mitral incompetence varies with the height of the arterial pressure, as shown directly in experimental animals $(8,9)$ and indirectly by auscultation (10-12) and hemodynamic changes $(13,14)$ in man. The lesion that has been studied in animals was in each case an acute one, produced by inserting a rigid hollow tube to act as a regurgitant pathway from ventricle to atrium. The quantitative data obtained are therefore of limited application to man, where the lesion is chronic and where a rigid nondistensible orifice is probably not a good analogy for the valve lesion in many patients, especially not in those with annular dilatation and functional incompetence. The present study was undertaken because no quantitative information was available in man on the relationship between arterial pressure and

\footnotetext{
* Submitted for publication March 9, 1964 ; accepted July 9, 1964.

Supported by grant-G28 from the National Heart Foundation of Australia.

Presented in part to the Annual Meeting of the Cardiac Society of Australia and New Zealand, Sydney, June 1963.

† Smith, Kline \& French Research Fellow.

\$ Supported by the Life Insurance Medical Research Fund of Australia and New Zealand.
}

regurgitant flow, and we hoped that in individual patients measurement of this relationship might identify to some extent the nature of the underlying lesion.

We have shown previously that mitral regurgitant flow can be measured satisfactorily in man by the double dye dilution method applied by simultaneous needle punctures of the left atrium and ventricle (15). In this study we have measured the effects of changing the arterial pressure in patients with rheumatic mitral incompetence. The individual results have been related to structural data about the underlying lesion obtained later.

\section{Methods}

Fourty-four patients were studied during left heart catheterization for the evaluation of mitral valve disease. All had obvious mitral incompetence that was considered to be of rheumatic origin, although there was a definite history of this in only 15 . None had aortic stenosis, significant aortic incompetence, or hypertensive or ischemic heart disease. The mitral incompetence varied from mild to severe, and the amount of associated stenosis from nil to moderately severe. Twenty-six had atrial fibrillation and the remainder sinus rhythm.

In each patient control measurements were made of forward cardiac output, mitral regurgitant flow, heart rate, and pressures in the left heart chambers. The arterial pressure was then changed by giving either a pressor drug or glyceryl trinitrate, and a second set of measurements was made.

In 18 patients, no drug was given between two measurements made 5 minutes apart to assess spontaneous variations.

In 12 patients (group one), norepinephrine bitartrate ${ }^{1}$ was infused intravenously at a constant rate of 10 to 20 $\mu \mathrm{g}$ of base per minute to raise the arterial pressure while also providing a positive inotropic effect on heart muscle (16). In 11 patients (group two) the arterial pressure was raised without any associated effect on heart muscle. In four methoxamine hydrochloride ${ }^{2}$ was given at 0.5 to

${ }^{1}$ Levophed, Winthrop Laboratories, New York, N. Y.

2 Vasylox, kindly supplied by Burroughs Wellcome (Aust.), Ltd., Sydney, Australia. 


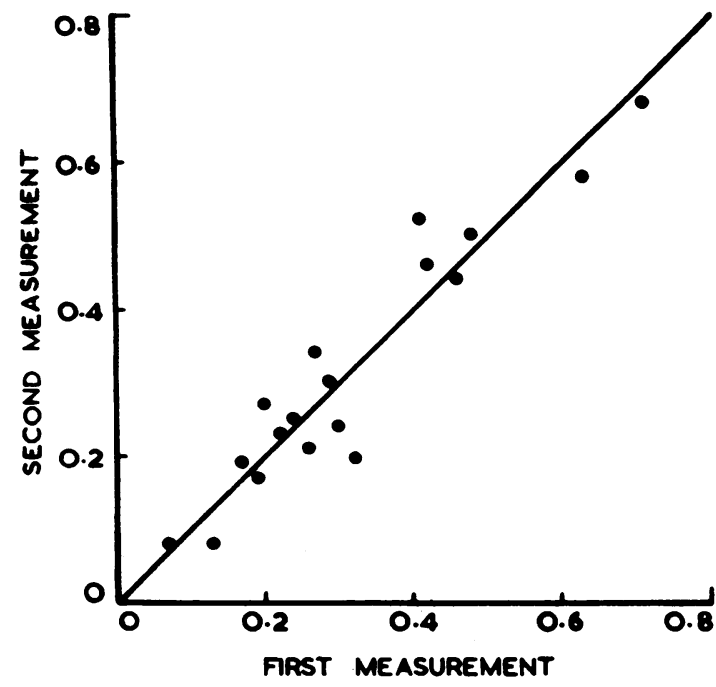

REGURGITANT FRACTION

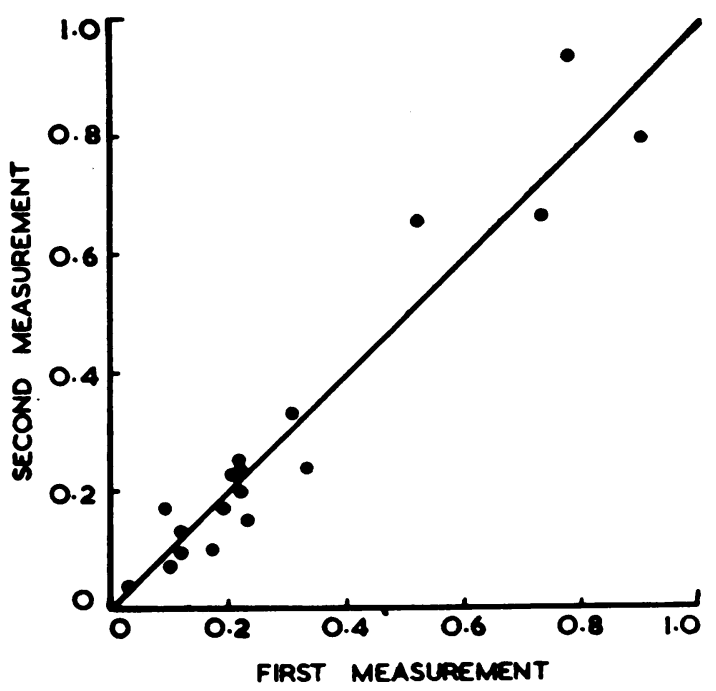

REGURGITANT ORIFICE

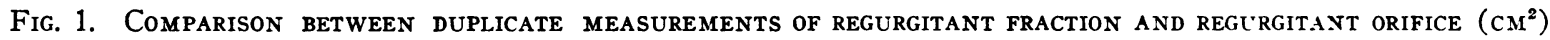
5 MINUTES APART IN 18 PATIENTS.

$2 \mathrm{mg}$ per minute (16), in four synthetic angiotensin II 3 at $1.0 \mu \mathrm{g}$ per minute (17), and in three norepinephrine was given as above after prior administration of pronethalol,4 $2 \mathrm{mg}$ per $\mathrm{kg}$ body weight intravenously, to produce myocardial adrenergic blockade (18). In each case the pressor drug was given at constant rate for 5 minutes before and 2 to 3 minutes during the second measurements, which were thereby made during a new steady level of arterial pressure. In one patient, the effect of norepinephrine was measured both before and after blockade of its inotropic action by pronethalol.

In four patients (group three), $0.6 \mathrm{mg}$ glyceryl trinitrate was crushed and given sublingually to lower the arterial pressure, the second measurements being made between 4 and 6 minutes later.

Mitral regurgitant flow and forward cardiac output were measured together by the double dye dilution principle. Details of the methods used and of the subsequent calculations have been given previously (15). We placed particular emphasis on three features of technique: the left ventricle was entered percutaneously so that the dye injection was reliably made into the body of that chamber with a "spray-tip" needle; the transseptal needle tip in the left atrium was positioned as close as possible to the mitral valve for sampling the atrial dilution curve; any measurement in which one or more ectopic ventricular beats occurred at the time of dye injection was discarded, and the injection was repeated.

\footnotetext{
${ }^{3}$ Hypertensin, kindly supplied by Ciba Ltd., Sydney, Australia.

4 Alderlin, kindly supplied by Imperial Chemical Industries of Australia and New Zealand Ltd., Melbourne, Australia.
}

Six channels of a Sanborn Polybeam photographic recorder were used, three for equisensitive strain-gauge measurements of pressure from the left atrium, ventricle, and brachial artery, two for equisensitive densitometer records of the atrial and arterial dye concentration curves, and one for the electrocardiogram (Figure 2). Pressures were averaged over several cardiac cycles at resting endexpiration, referred to the midchest level; mean pressure gradients were obtained by planimetry. Forward flow was derived from the arterial dilution curve. The regurgitant fraction (the ratio of regurgitant to total left ventricular output) was obtained as the ratio of areas of the extrapolated atrial and arterial concentration curves. Regurgitant flow was derived from the regurgitant fraction and the forward flow. The formula used for calculation of both regurgitant and stenotic orifices was: orifice area $\left(\mathrm{cm}^{2}\right)=$ [valve flow (milliliters per second) $] /[0.7 \times 44.5 \times \sqrt{\text { pressure gradient (millimeters }}$ $\mathrm{Hg}$ )].

For descriptive purposes, the patients were divided arbitrarily into those with "pure incompetence" and those with "significant associated stenosis" by defining the latter as a stenotic orifice of less than $2.0 \mathrm{~cm}^{2}$, calculated from the hemodynamic data.

\section{Results}

No untoward reactions were seen to the drugs used in this study. Their administration and the subsequent measurements prolonged the diagnostic study by some 10 minutes and required reinsertion of the left ventricular needle. There were no immediate complications, but one patient de- 
TABLE I

Average hemodynamic measurements before and after changing arterial pressure*

\begin{tabular}{|c|c|c|c|c|c|c|c|}
\hline & $\begin{array}{l}\text { Heart } \\
\text { rate }\end{array}$ & 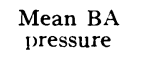 & $\begin{array}{c}\text { Mean LA } \\
\text { pressure }\end{array}$ & $\underset{\text { index }}{\text { Cardiac }}$ & $\begin{array}{c}\text { Regurgitant } \\
\text { fraction }\end{array}$ & $\begin{array}{l}\text { Regurgitant } \\
\text { flow index }\end{array}$ & $\begin{array}{c}\text { Regurgitant } \\
\text { orifice }\end{array}$ \\
\hline & & $m m \mathrm{Hg}$ & $m m \mathrm{Hg}$ & $L / \min / m^{2}$ & & $L / \min / m^{2}$ & $\mathrm{~cm}^{2}$ \\
\hline \multicolumn{8}{|c|}{ Groups 1 and $2:$ all pressor drugs (23 patients) } \\
\hline $\begin{array}{l}\text { Control } \\
\text { Mean change } \\
\text { (SEM) } \\
\text { Significance }\end{array}$ & $\begin{array}{l}79 \\
-4 \\
(2.4) \\
\mathrm{NS}\end{array}$ & $\begin{array}{c}89 \\
+20 \\
(2.2) \\
p<0.001\end{array}$ & $\begin{array}{c}22 \\
+10 \\
(1.6) \\
p<0.001\end{array}$ & $\begin{array}{c}2.59 \\
-0.10 \\
(0.10) \\
\text { NS }\end{array}$ & $\begin{array}{c}0.37 \\
+0.11 \\
(0.03) \\
\mathrm{p}<0.01\end{array}$ & $\begin{array}{c}2.38 \\
+1.13 \\
(0.60) \\
\text { NS }\end{array}$ & $\begin{array}{r}0.53 \\
+0.40 \\
(0.16) \\
\mathrm{p}<.05\end{array}$ \\
\hline \multicolumn{8}{|c|}{ Group 1 : inotropic pressor drug (12 patients) } \\
\hline $\begin{array}{l}\text { Control } \\
\text { Mean change } \\
\text { (SEM) } \\
\text { Significance }\end{array}$ & $\begin{array}{c}78 \\
-4 \\
(3.2) \\
\text { NS }\end{array}$ & $\begin{array}{c}87 \\
+22 \\
(3.6) \\
\mathrm{p}<0.001\end{array}$ & $\begin{array}{c}22 \\
+12 \\
(2.5) \\
\mathrm{p}<0.001\end{array}$ & $\begin{array}{c}2.86 \\
+0.14 \\
(0.07) \\
\text { NS }\end{array}$ & $\begin{array}{c}0.41 \\
+0.04 \\
(0.03) \\
\text { NS }\end{array}$ & $\begin{array}{c}3.08 \\
+0.28 \\
(0.77) \\
\text { NS }\end{array}$ & $\begin{array}{r}0.67 \\
+0.12 \\
(0.13) \\
\mathrm{NS}\end{array}$ \\
\hline \multicolumn{8}{|c|}{ Group 2: noninotropic pressor drug (11 patients) } \\
\hline $\begin{array}{l}\text { Control } \\
\text { Mean change } \\
\text { (SEM) } \\
\text { Significance }\end{array}$ & $\begin{array}{l}81 \\
-4 \\
(3.7) \\
\mathrm{NS}\end{array}$ & $\begin{array}{c}92 \\
+18 \\
(2.5) \\
\mathrm{p}<0.001\end{array}$ & $\begin{array}{c}22 \\
+8 \\
(1.9) \\
\mathrm{p}<0.01\end{array}$ & $\begin{array}{c}2.29 \\
-0.37 \\
(0.13) \\
\mathrm{p}<0.02\end{array}$ & $\begin{array}{c}0.33 \\
+0.19 \\
(0.04) \\
\mathrm{p}<0.01\end{array}$ & $\begin{array}{c}1.63 \\
+1.93 \\
(0.92) \\
\mathrm{p}<0.05\end{array}$ & $\begin{array}{r}0.37 \\
+0.70 \\
(0.29) \\
\mathrm{p}<.05\end{array}$ \\
\hline \multicolumn{8}{|c|}{ Group 3: glyceryl trinitrate (4 patients) } \\
\hline $\begin{array}{l}\text { Control } \\
\text { Mean change } \\
\text { (SEM) } \\
\text { Significance }\end{array}$ & $\begin{array}{c}87 \\
+1 \\
(1.1) \\
\text { NS }\end{array}$ & $\begin{array}{c}89 \\
-22 \\
(5.3) \\
\mathrm{p}<0.05\end{array}$ & $\begin{array}{l}29 \\
-9 \\
(3.3) \\
\text { NS }\end{array}$ & $\begin{array}{c}2.60 \\
-0.39 \\
(0.21) \\
\text { NS }\end{array}$ & $\begin{array}{c}0.45 \\
-.08 \\
(0.04) \\
\text { NS }\end{array}$ & $\begin{array}{c}5.34 \\
-1.38 \\
(0.68) \\
\text { NS }\end{array}$ & $\begin{array}{r}0.67 \\
-0.38 \\
(0.24) \\
\text { NS }\end{array}$ \\
\hline
\end{tabular}

$* \mathrm{BA}=$ brachial artery $; \mathrm{LA}=$ left atrium $; \mathrm{SEM}=$ standard error of mean change.

veloped pericardial pain and fever for several days after the study, a syndrome we attributed to the presence of blood in the pericardium (15). No evidence of infection was found, and the condition subsided spontaneously after 10 days. Considerable pericardial adhesions were found in this patient at surgery 3 months later, in contrast to the findings in other patients studied who have subsequently undergone surgery.

Spontaneous variability of measurements. The duplicate measurements in 18 patients were made 5 minutes apart, under conditions identical to those in subsequent studies. There were no significant variations in the left heart pressures or in heart rate. The standard deviations (19) of the measurements of flow were: cardiac index, $\pm 0.20 \mathrm{~L}$ per minute per $\mathrm{m}^{2}$ ( $8.5 \%$ of the mean) ; regurgitant fraction, \pm 0.04 (12\% of the mean) ; regurgitant flow, $\pm 0.26 \mathrm{~L}$ per minute per $\mathrm{m}^{2}$ (18\% of the mean); calculated regurgitant orifice, \pm 0.05 $\mathrm{cm}^{2}$ ( $17 \%$ of the mean). The individual values of regurgitant fraction and regurgitant orifice are shown in Figure 1. Over this range of regurgitant fraction ( 0.08 to 0.70$)$, there was no tendency for the variation to depend on the magnitude of the measurement.

During studies in other patients with mitral incompetence, we found much larger variations than these in the measurement of regurgitant flow when the left ventricle was entered by retrograde catheterization rather than by percutaneous puncture. We have also noted that dye injections in which ectopic ventricular beats occurred sometimes produced grossly discordant results.

Effects of raising arterial pressure. The original records obtained in one study are reproduced in Figure 2. In 23 patients, the average increase in arterial mean pressure was $20 \mathrm{~mm} \mathrm{Hg}$ (Table $\mathrm{I}$, top). This was associated with an average increase of $45 \%$ in the regurgitant flow without change in the forward flow. This rise in regurgitant flow was out of proportion to the rise in pressure gradient between ventricle and atrium; there was therefore an increase in the calculated regurgitant orifice averaging 66\%. The changes varied considerably among different patients, but the increases in regurgitant fraction and regurgitant orifice were statistically significant. 

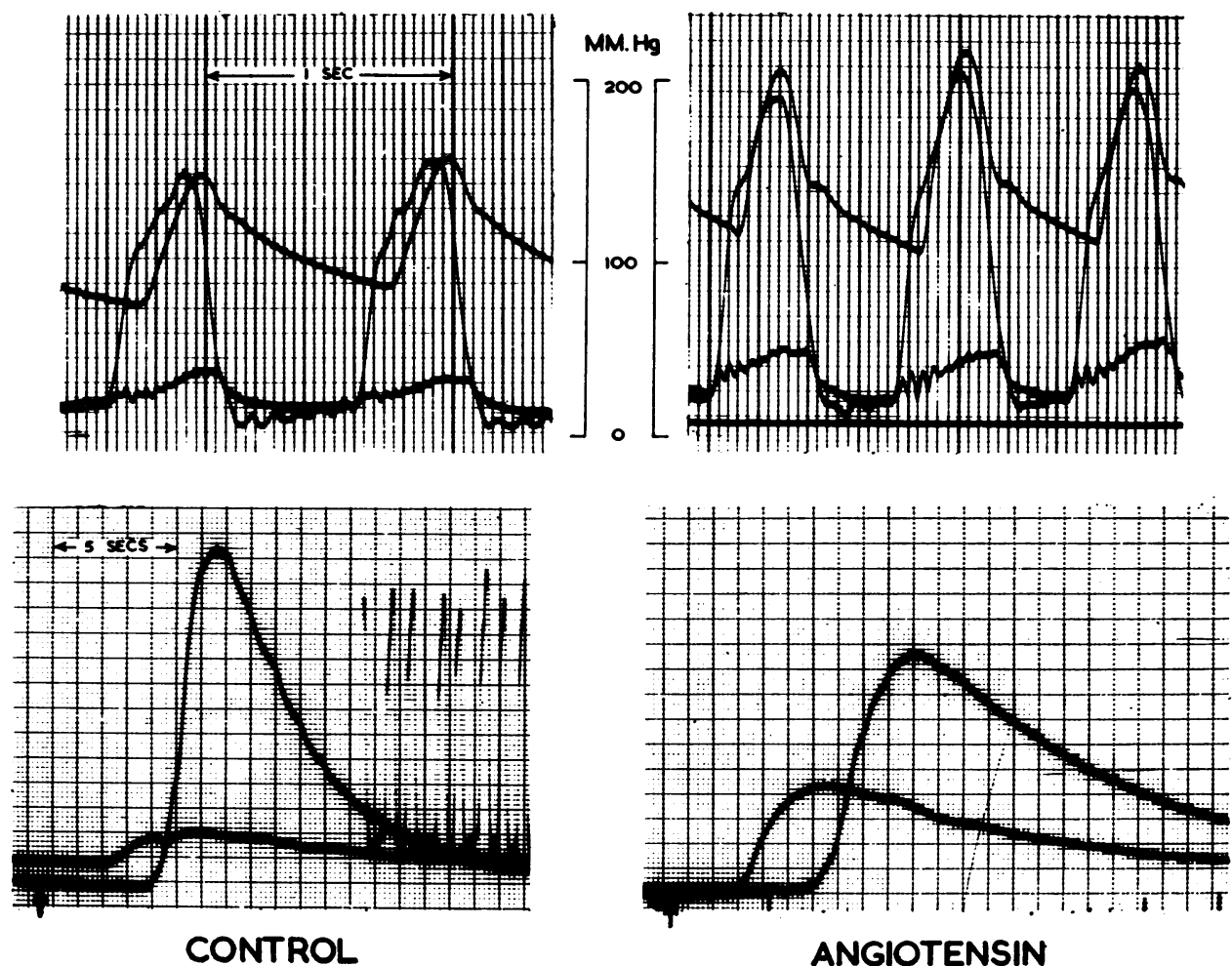

ANGIOTENSIN

Fig. 2. ORIGINAL RECORDS OF THE STUDY IN ONE PATIENT. Left: recordings at rest of pressures from the left atrium, left ventricle, and brachial artery (upper), and dilution curves from the left atrium and brachial artery (lower) after dye injection (at arrow) into the left ventricle. Right: pressures and dye curves repeated during intravenous infusion of angiotensin, $1 \mu \mathrm{g}$ per minute. Mean arterial pressure changed from 109 to $137 \mathrm{~mm} \mathrm{Hg}$, cardiac index from 1.82 to $1.15 \mathrm{~L}$ per minute per $\mathrm{m}^{2}$, regurgitant fraction from 0.14 to 0.47 , and calculated regurgitant orifice from 0.07 to $0.13 \mathrm{~cm}^{2}$.

When the rise in arterial pressure was produced by norepinephrine (group one, Table I), the results differed from those seen with noninotropic pressor drugs (group two, Table I). The changes in arterial pressure, atrial pressure, and heart rate in each group were similar. In group one there were small average changes in the forward flow, regurgitant fraction, regurgitant flow, and regurgitant orifice, none of which was statistically significant. In group two, however, the forward flow fell by an average of $16 \%$, whereas the regurgitant flow increased by $120 \%$ and the regurgitant orifice by $170 \%$, all of these changes being significant.

These differences between groups one and two suggested that the inotropic action of norepinephrine had limited or prevented the increase in regurgitation otherwise caused by the rise in ar- terial pressure. To verify this, measurements were made in one patient during increases of arterial pressure by norepinephrine, both before and after blocking its inotropic action with pronethalol. The results are illustrated in Figure 3 . They show that for the same increase in mean arterial pressure, the regurgitant orifice increased from $0.5 \mathrm{~cm}^{2}$ to $1.0 \mathrm{~cm}^{2}$ with norepinephrine alone, but to $2.4 \mathrm{~cm}^{2}$ with norepinephrine after pronethalol.

Norepinephrine increased the maximal rate of pressure rise in the left ventricle from an average in group one of 1,060 to $1,470 \mathrm{~mm} \mathrm{Hg}$ per second $(\mathrm{p}<0.001)$ and thereby shortened the duration of isometric systole from an average of 0.08 to 0.06 second $(p<0.05)$, despite the rise in arterial pressure. The noninotropic stimuli used in group two did not change the rate of pressure rise (average, 1,080 $\mathrm{mm} \mathrm{Hg}$ per second), and isometric 


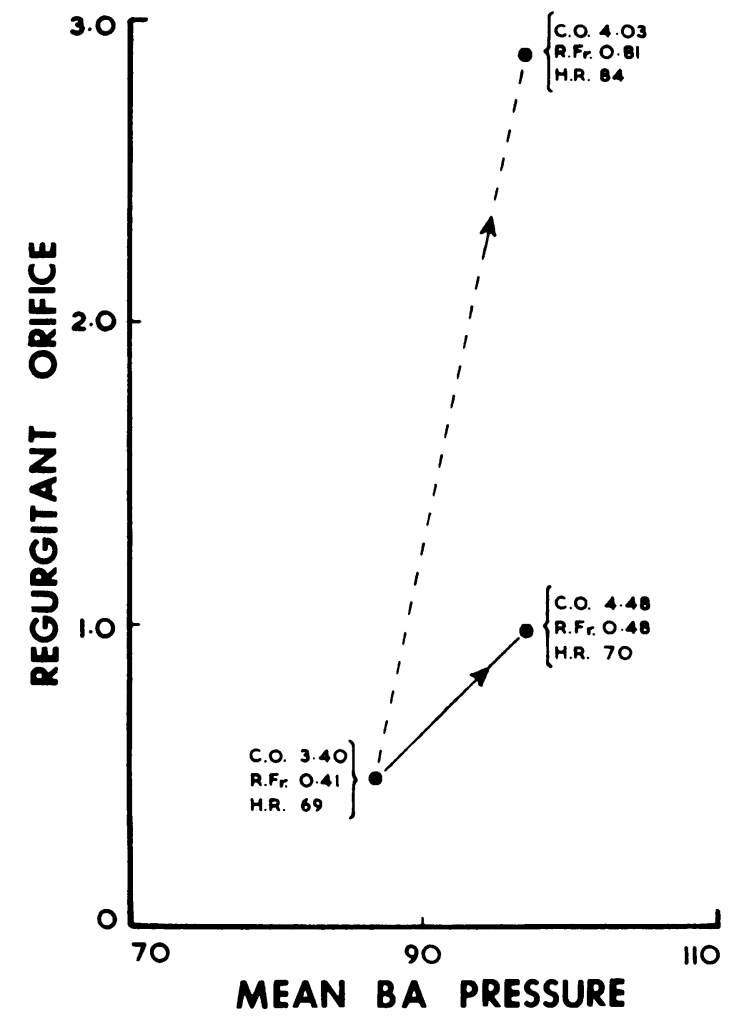

Fig. 3. Calcllated Regurgitant orifice related to ARTERIAL PRESSURE IN ONE PATIENT DURING INFUSION OF NOREPINEPHRINE BEFORE (solid line) AND AFTER (dashed line) BLOCKADE OF ITS inOtROPIC ACTION BY PRONETHALOL. Values of cardiac output (C.O.), regurgitant fraction (R.Fr.), and heart rate (H.R.) at each measurement are shown.

systole was therefore prolonged, the average increasing from 0.08 to 0.09 second $(p<0.02)$. These changes were uniform and theoretically favored production of a greater regurgitant flow in group two (20). Their magnitude, however, did not seem enough to explain all of the difference found between groups one and two. Neither the duration of ejection (average, 0.26 second) nor of the period of regurgitation (average, 0.40 second) was systematically changed in either group.

Apparently, therefore, enhanced ventricular contractility was an important factor influencing the incompetence when arterial pressure was raised by norepinephrine. This factor was absent in the patients studied in group two. Figure 4 (right) illustrates, however, that the changes in severity of incompetence in this group, as repre- sented by the changes in calculated regurgitant orifice, were not uniform. In seven patients, only small changes were seen, averaging $+0.05 \mathrm{~cm}^{2}$ with $\mathrm{SD} \pm 0.10 \mathrm{~cm}^{2}$, whereas in four there were very large increases ranging from +1.1 to +2.4 $\mathrm{cm}^{2}$. These differences were not related to the particular noninotropic pressor drug used, nor to the presence of atrial fibrillation in 7 of these 11 patients. The presence of associated mitral stenosis (marked MS in Figure 4) was, however, one factor distinguishing these patients. Other factors, not mutually independent, were the magnitude of the initial calculated regurgitant orifice and the structural nature of the lesion found subsequently. These data are given in Table II.

Of seven patients in group two who showed changes less than $0.2 \mathrm{~cm}^{2}$ in the regurgitant orifice, four had significant stenosis of the valve. At surgery in three of these, both valve commissures were found to be fused. In the three with pure incompetence, one showed calcification of the valve radiologically, and one at surgery had a rigid calcified valve with fused margins and no annular dilatation. In six of these seven patients the initial regurgitant orifice was less than $0.16 \mathrm{~cm}^{2}$, and in the other it was $0.62 \mathrm{~cm}^{2}$.

In all four patients in group two who showed large changes in the regurgitant orifice, the orifice was large initially $\left(0.20\right.$ to $\left.1.5 \mathrm{~cm}^{2}\right)$, and stenosis was absent. Surgical findings are available in three of the four. In one, an extensive tear had been made in the anterior valve leaflet at a previous valvotomy, and this had been followed by progressive left ventricular dilatation. In one there was gross destructive valve disease with annular dilatation, and in one there was annular dilatation alone.

In group one, five patients showed changes less than $0.1 \mathrm{~cm}^{2}$ in regurgitant orifice. The initial orifice was small in three of the five $(0.10$ to $\left.0.15 \mathrm{~cm}^{2}\right)$; two of these had significant stenosis, and each at operation had fusion of both valve commissures. The initial orifice was large in two of the five $\left(0.63\right.$ and $\left.2.1 \mathrm{~cm}^{2}\right)$; one of these showed dense calcification of the valve radiologically, but no surgical data are available in either.

The other seven patients in group one showed changes in regurgitant orifice greater than 0.2 

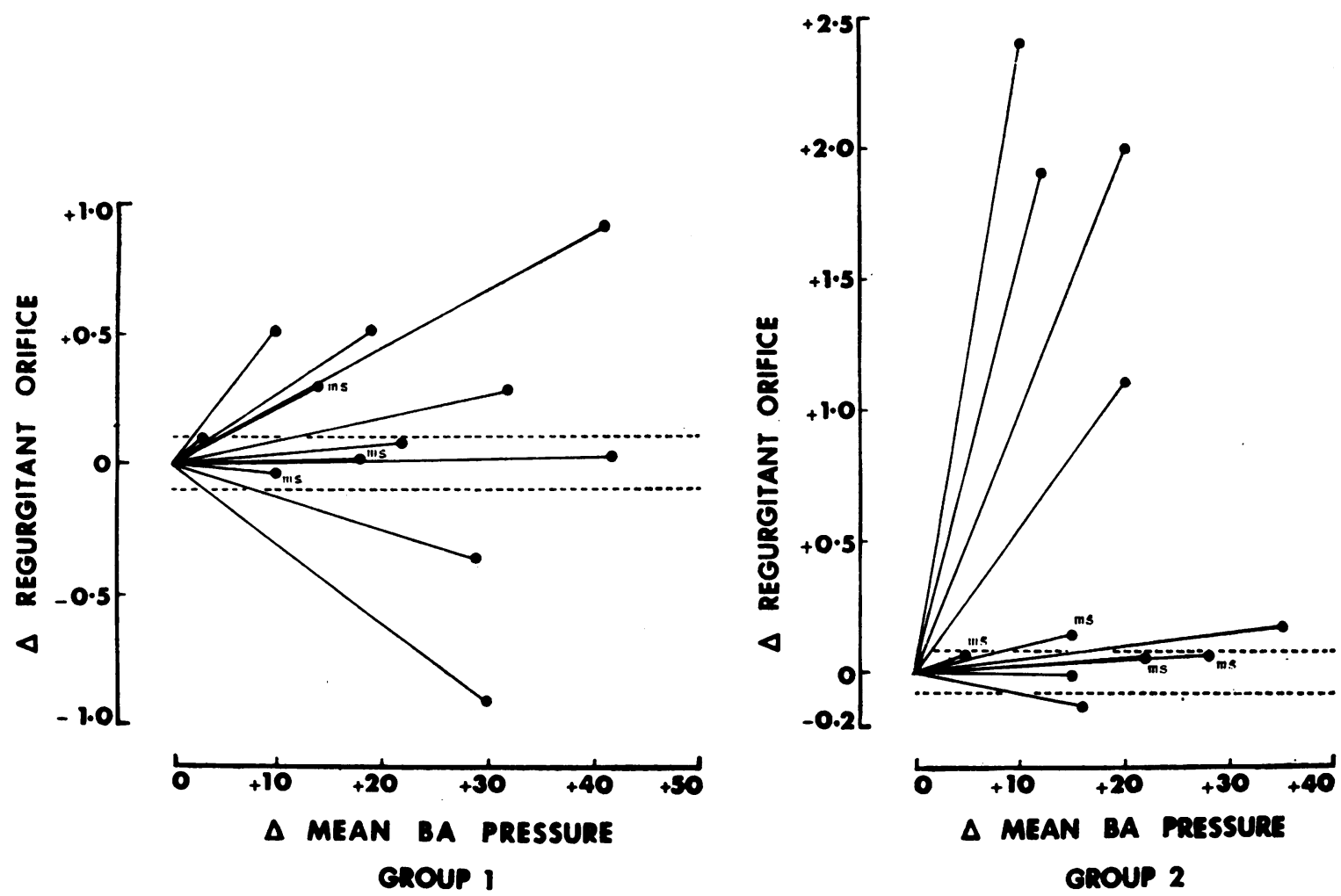

Fig. 4. Changes in Regurgitation orifice ( $\mathrm{Cm}^{2}$ ) Related to the rise in mean arterial (BA) PRessure, usING NOREPINEPHRINE (GROUP ONE) AND A NONINOTROPIC PRESSOR DRUG (GROUP TWO). MS signifies patients with significant associated mitral stenosis. Dashed lines indicate $2 \mathrm{SD}$ of duplicate measurements.

$\mathrm{cm}^{2}$, increases in five patients and reductions in two. The patient with an initial regurgitant orifice of $0.19 \mathrm{~cm}^{2}$ also had significant stenosis, but the surgical findings were unusual in that there was no fusion of the posterior commissure. In the other six the initial orifice was large, ranging from 0.28 to $2.0 \mathrm{~cm}^{2}$, and stenosis was absent. Structural information is available in three, all of whom had significant annular dilatation, associated in two with severe fibrotic valve disease and in one with a perforation in the anterior valve leaflet.

Effects of lowering arterial pressure. The average findings in the four patients in group three are given in Table I (below). The changes in each case were uniform in direction but varied in magnitude. On the average the mean arterial pressure was lowered by $22 \mathrm{~mm} \mathrm{Hg}$; left atrial pressure also fell, both forward and regurgitant flow fell, and there was a large fall in the calculated regurgitant orifice. In Figure 5 are shown the individual changes in the regurgitant orifice, suggesting a pattern inverse but similar to that found in group two (Figure 4). These changes are detailed in Table II (group three). The regurgitant orifice fell by $0.2 \mathrm{~cm}^{2}$ or less in three patients; in them the initial regurgitant orifice ranged from 0.21 to $0.41 \mathrm{~cm}^{2}$; one of the three had significant stenosis as well and was later shown to have fusion of both valve commissures; another had a markedly retracted fibrotic valve without stenosis and without annular dilatation. No surgical information is available in the third, nor in the one patient with an initial orifice of 1.8 $\mathrm{cm}^{2}$ that decreased to $0.7 \mathrm{~cm}^{2}$ when arterial pressure was reduced.

\section{Discussion}

Earlier applications in man of the double dye dilution method for measuring mitral regurgitant flow $(21,22)$ featured poor reproducibility and occasional grossly anomalous results. These problems have not been encountered with present 
TABLE II

The initial value and change in the calculated regurgitant orifice in individual patients, related to the structural details of the mitral valve obtained subsequently at surgery or autopsy

\begin{tabular}{|c|c|c|c|}
\hline \multicolumn{2}{|c|}{$\begin{array}{l}\text { Calculated regurgitant } \\
\text { orifice }\end{array}$} & \multirow{2}{*}{$\begin{array}{l}\text { Calculated } \\
\text { stenotic } \\
\text { orifice }\end{array}$} & \multirow[b]{2}{*}{ Structural detail of valve } \\
\hline $\overrightarrow{\text { Control }}$ & Change & & \\
\hline & $\mathrm{cm}^{2}$ & $\mathrm{~cm}^{2}$ & \\
\hline \multicolumn{4}{|c|}{ Group 1} \\
\hline 0.10 & +0.02 & 1.0 & Both commissures fused. \\
\hline 0.12 & +0.02 & & \\
\hline 0.15 & -0.04 & 1.1 & Eccentric orifice. Both commissures fused. \\
\hline 0.19 & +0.29 & 1.4 & $\begin{array}{l}\text { Anterior commissure fused across midline. Regurgi- } \\
\text { tation at nonfused posterior commissure. }\end{array}$ \\
\hline 0.28 & +0.28 & & \\
\hline 0.40 & +0.50 & & $\begin{array}{l}\text { Fused anterior commissure. Contracted posterior } \\
\text { leaflet. Annular dilatation. }\end{array}$ \\
\hline $0.50^{*}$ & +0.50 & & \multirow[t]{4}{*}{$\begin{array}{l}\text { Scarring and retraction of both leaflets. No } \\
\text { fusion. Gross anmular dilatation. }\end{array}$} \\
\hline 0.63 & +0.08 & & \\
\hline 0.66 & -0.36 & & \\
\hline 0.87 & +0.93 & & \\
\hline 2.0 & -0.9 & & $\begin{array}{l}\text { Mobile leaflets. Hole } 6 \mathrm{~mm} \text { in diameter in anterior } \\
\text { leaflet. Marked annular dilatation. }\end{array}$ \\
\hline 2.1 & +0.1 & & $\mathrm{X}$ ray shows dense valve calcification. \\
\hline \multicolumn{4}{|l|}{ Group 2} \\
\hline 0.03 & +0.15 & 1.0 & $\begin{array}{l}\text { Gross calcification of both leaflets. Irregular } \\
\text { central slit-like orifice. }\end{array}$ \\
\hline 0.06 & +0.06 & 0.9 & \multirow[t]{2}{*}{$\begin{array}{l}\text { Tough fibrous leaflets. Both commissures fused. } \\
\text { Shortened chordae. }\end{array}$} \\
\hline 0.07 & +0.06 & 1.6 & \\
\hline 0.10 & +0.17 & \multirow{8}{*}{1.2} & $\mathrm{X}$ ray shows moderate valve calcification. \\
\hline 0.11 & +0.05 & & Calcified valve. Centrally placed orifice. \\
\hline 0.15 & -0.01 & & \\
\hline 0.30 & +1.1 & & $\begin{array}{l}\text { Incompetence produced by anterior leaflet tear at } \\
\text { previous valvotomy. }\end{array}$ \\
\hline $0.50^{*}$ & +2.4 & & $\begin{array}{l}\text { Scarring and retraction of both leaflets. No } \\
\text { fusion. Gross annular dilatation. }\end{array}$ \\
\hline 0.62 & -0.13 & & $\begin{array}{l}\text { Gross valve calcification. Fusion and contraction } \\
\text { of both leaflets. Rigid orifice. }\end{array}$ \\
\hline 0.69 & +1.8 & & \\
\hline 1.5 & +2.0 & & Leaflets normal. Gross annular dilatation. \\
\hline \multicolumn{4}{|l|}{ Group 3} \\
\hline 0.21 & -0.06 & \multirow{4}{*}{1.1} & \multirow{4}{*}{$\begin{array}{l}\text { Calcified. Central orifice. Both commissures fused. } \\
\text { Partly calcified. Both commissures fused. } \\
\text { Marked retraction by chordal shortening. }\end{array}$} \\
\hline 0.27 & -0.15 & & \\
\hline 0.41 & -0.20 & & \\
\hline 1.8 & -1.1 & & \\
\hline
\end{tabular}

* Same patient; also illustrated in Figure 3.

techniques (15), provided that measurements are discarded if ectopic ventricular beats occur. The reproducibility shown here is similar to that found recently by Sinclair-Smith and his colleagues in replicate measurements (23).
The accuracy of the method cannot be confirmed at present in man, but remarkably precise calculations of the regurgitant orifice were obtained using the method in dogs with chronic experimental lesions (24). For the present study, valid 
comparability of two measurements is more important than absolute accuracy in either, since any conclusions here will be influenced very little by the presence of a constant error in both measurements. There were no large changes in heart rate in the study, and flow measurements by the double dye dilution principle are inherently unaffected by changes in the volumes of the heart chambers (25). There are, therefore, no reasons to expect the two measurements to lack comparability.

The general applicability of hydraulic principles to pulsatile flow through small openings in the mitral valve has been established $(26,27)$, although the appropriate orifice contraction coefficient has not been determined for mitral incompetence. At different pressures and flows through the valve, this coefficient may change in some patients but not enough to cause appreciable error in this study (27). The calculation of regurgitant orifice is used here as an index of the severity of incompetence at one measured pressure gradient between the ventricle and atrium. We emphasize that the figure obtained represents a mean functional orifice during systole. Its relationship to the true anatomic orifice of the valve will vary with the importance of several factors that cannot be assessed here, such as variation of the true orifice during systole, or hydraulic competition between the aortic and mitral orifices (20). Nevertheless, a large change of the calculated orifice in any patient will indicate a corresponding change in the degree of incompetence of the valve mechanism.

The effect of changes in arterial pressure on mitral incompetence was found to vary considerably among different patients. Two principal factors were identified to account for this, the nature of the mitral valve lesion and the functional state of the myocardium.

The influence of the valve lesion was seen most clearly in groups two and three, where no direct changes in myocardial function were produced. When arterial pressure was changed, ten of these fifteen patients showed little or no change in the regurgitant orifice ( $\pm 0.2 \mathrm{~cm}^{2}$ or less); the incompetence was mild initially in six of the ten and severe in four; surgical data were obtained in seven of the ten, and showed either

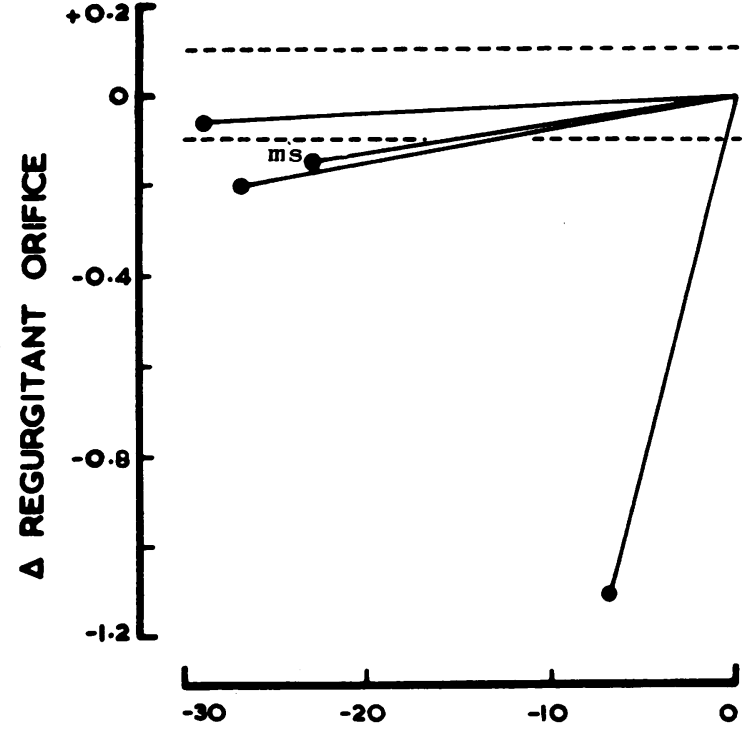

$\triangle$ MEAN BA pRESSURE

Fig. 5. Changes in calculated Regurgitant oriFICE $\left(\mathrm{CM}^{2}\right)$ RELATED TO THE FALL IN MEAN ARTERIAL PRESSURE IN FOUR PATIENTS GIVEN GLYCERYL TRINITRATE. MS indicates the patient with significant associated mitral stenosis. Dashed lines indicate $2 \mathrm{SD}$ of duplicate measurements.

stenosis with fusion of both commissures (in five) or rigid fibrosed valves (in two); there was no annular dilatation. In contrast the other five of the fifteen patients showed changes greater than $1.0 \mathrm{~cm}^{2}$ in the regurgitant orifice; in all five the incompetence was severe initially; surgical data were obtained in three, and each showed marked annular dilatation, with organic valve disease in two and without in one; there was no stenosis.

There were similar findings in the six patients of group one in whom surgical data were obtained. In two with stenosis and fusion of both commissures, the regurgitant orifice did not change, in one with stenosis but without fusion of the posterior commissure it increased by $0.29 \mathrm{~cm}^{2}$, and in three with organic valve lesions and annular dilatation it increased by $0.5 \mathrm{~cm}^{2}$ or more.

When the regurgitant orifice remained unchanged, these effects of arterial pressure on mitral incompetence in man were similar to those observed in experimental animals with a rigid incompetent orifice $(8,9)$. The nature of the valve lesion in those patients further strengthens this similarity, in that rigidity of the diseased 
valve was a common feature. The patients who showed large changes in the regurgitant orifice have no analogy in previous experimental studies. The presence of annular dilatation was one factor distinguishing them, although it may not have been the only one.

The role of myocardial function in modifying the incompetence was seen by comparing both the average changes in groups one and two and the absolute changes in one patient (Figure 3 ). A limiting influence of norepinephrine on the regurgitant orifice was demonstrated only in patients in whom the orifice changed and who therefore probably had annular dilatation. In two patients, one known to have annular dilatation, the orifice actually diminished by $50 \%$ despite the increased arterial pressure. The mechanism of this effect was not identified. It appeared to result from the inotropic properties of norepinephrine, since there was no evidence that chronotropic changes were important. Changes in the rate of ventricular contraction did not seem an adequate explanation, although Wiggers and Feil (8) considered them important. Part of the annular margin is formed of muscle ( 7 ) that shortens actively in systole (28); enhanced contraction of this muscle would diminish incompetence caused by annular dilatation. Alternatively, a reduction in left ventricular volume caused by norepinephrine would reduce lateral tension on the mitral valve leaflets (7) and thereby reduce the incompetence.

Several general conclusions may be made from these findings. The structural nature of the valve lesion in mitral incompetence appears to determine whether the incompetence itself varies under different functional conditions or remains fixed. In the latter case, changes in arterial pressure will cause changes in regurgitant flow predictable from the changes in pressure gradient across the valve, and changes in myocardial function will influence the incompetence relatively little. In the former case, however, the incompetence itself will increase when arterial pressure rises and will depend also upon the function of the myocardium. It would be in this type of patient that incompetence is increased in severity during periods of cardiac decompensation (29) and that progressive left ventricular dilatation and failure are likely to occur. It seems probable that in this way the natural history of patients with mitral incompetence will depend to a considerable extent on the functional behavior of their particular valve lesion.

Apparently the information gained in individual patients is not at present of great practical value in their preoperative evaluation. Our correlation with surgical findings has shown that if the calculated regurgitant orifice changes significantly, the presence of annular dilatation can be predicted with some certainty. Unless there is an element of associated stenosis, however, no information is obtained regarding the presence or absence of organic valve disease. It has not been possible therefore to distinguish patients with a primary myocardial fault and pure annular dilatation from those with an organic valve lesion also, in whom the annular dilatation may have arisen from either a primary or secondary myocardial fault. It is possible. however, that the presence of annular dilatation preoperatively will prove to influence adversely the long-term results of prosthetic mitral valve replacements; in this case its preoperative recognition could become of some importance.

\section{Summary}

Measurements of mitral incompetence were made in patients before and after raising or lowering the arterial pressure by vasoactive drugs.

In some patients, the mitral regurgitant flow changed predictably according to the change in pressure gradient across the valve, the calculated regurgitant orifice remaining unchanged. In these patients, the mitral incompetence was usually not severe, there was often some associated mitral stenosis, and the valve orifice at surgery was found to be limited by fibrosis or calcification.

In others there were disproportionate changes in regurgitant flow and large changes in the calculated regurgitant orifice. These patients had severe incompetence, rarely with stenosis, and at surgery had mitral annular dilatation, with or without an organic valve lesion. A positive inotropic stimulus was found in these patients to reduce regurgitant flow and to reduce the calculated regurgitant orifice. 


\section{Acknowledgments}

We acknowledge the assistance given during this study by Drs. H. Peak, G. McClatchie, and D. Collison, medical registrars to the Unit. We are grateful to Prof. P. I. Korner for his advice in preparing the manuscript.

\section{References}

1. Brock, R. C. The surgical and pathological anatomy of the mitral valve. Brit. Heart J. 1952, 14, 489.

2. Harken, D. E. Mitral regurgitation. A group of surgical problems. Amer. J. Cardiol. 1958, 2, 263.

3. Kay, E. B., D. Mendelsohn, Jr., and H. A. Zimmerman. The role of surgery in the treatment of mitral regurgitation. Progr. cardiovasc. Dis. 1961, 4, 259.

4. Bentivoglio, L., J. Uricchio, and H. Goldberg. Clinical and hemodynamic features of advanced rheumatic mitral regurgitation. Review of sixty-five patients. Amer. J. Med. 1961, 30, 372.

5. Levy, M. J., and J. E. Edwards. Anatomy of mitral insufficiency. Progr. cardiovasc. Dis. 1962, 5, 119.

6. Soulié, P., P. Chiche, and M. Caramanian. Insuffisance mitrale. Anatomie pathologique et variétés étiologiques. Coeur Med. intern. 1962, 1, 345.

7. Braunwald, N. S., and A. G. Morrow. Prosthetic reconstruction of the mitral valve. Applications in the correction of mitral stenosis and mitral regurgitation. Progr. cardiovasc. Dis. 1963, 5, 313.

8. Wiggers, C. J., and H. Feil. The cardio-dynamics of mitral insufficiency. Heart 1922, 9, 149.

9. Braunwald, E., G. H. Welch, Jr., and S. J. Sarnoff. Hemodynamic effects of quantitatively varied experimental mitral regurgitation. Circulat. Res. 1957, 5, 539.

10. McMichael, J., and J. P. Shilling ford. The role of valvular incompetence in heart failure. Brit. med. J. 1957, 1, 537 .

11. Barlow, J., and J. P. Shillingford. The use of amyl nitrite in differentiating mitral and aortic systolic murmurs. Brit. Heart J. 1958, 20, 162.

12. Perloff, J. K., and W. P. Harvey. Auscultatory and phonocardiographic manifestations of pure mitral regurgitation. Progr. cardiovasc. Dis. 1962, 5, 172.

13. Braunwald, E., G. H. Welch, Jr., and A. G. Morrow. The effects of acutely increased systemic resistance on the left atrial pressure pulse: a method for the clinical detection of mitral insufficiency. J. clin. Invest. 1958, 37, 35.

14. Yu, P. N., J. K. Finlayson, and M. N. Luria. Indicator-dilution curves during methoxamine infusion in patients with mitral valvular diseases. Circulat. Res. 1961, 9, 319.
15. Jose, A. D., and L. Bernstein. Mitral regurgitant flow and left ventricular function in patients with mitral valve disease. Circulation 1962, 26, 1241.

16. Goldberg, L. I., R. D. Bloodwell, E. Braunwald, and A. G. Morrow. The direct effects of norepinephrine, epinephrine, and methoxamine on myocardial contractile force in man. Circulation 1960, 22, 1125.

17. Downing, S. E., and E. H. Sonnenblick. Effects of continuous administration of angiotensin II on ventricular performance. J. appl. Physiol. 1963, 18, 585.

18. Black, J. W., and J. S. Stephenson. Pharmacology of a new adrenergic beta-receptor-blocking compound (nethalide). Lancet 1962, 2, 311.

19. Mainland, D. in Methods in Medical Research, J. M. Steele, Ed. Chicago, Year Book Publishers, 1954, vol. 6, p. 178.

20. Rodbard, S., and F. Williams. The dynamics of mitral insufficiency. Amer. Heart J. 1954, 48, 521.

21. Woodward, E., Jr., H. J. C. Swan, and E. H. Wood. Evaluation of a method for detection of mitral regurgitation from indicator-dilution curves recorded from the left atrium. Proc. Mayo Clin. 1957, 32, 525.

22. Levinson, G. E., S. W. Stein, R. A. Carleton, and W. H. Abelman. Measurement of mitral regurgitation in man from simultaneous atrial and arterial dilution curves after ventricular injection. Circulation 1961, 24, 720.

23. Sinclair-Smith, B. C. Personal communication.

24. Newcombe, C. P., J. D. Sinclair, D. E. Donald, and E. H. Wood. Detection and assessment of mitral regurgitation by left atrial indicator-dilution curves. Circulat. Res. 1961, 9, 1196.

25. Lacy, W. W., W. H. Goodson, W. G. Wheeler, and E. V. Newman. Theoretical and practical requirements for the valid measurement by indicator-dilution of regurgitant flow across incompetent valves. Circulat. Res. 1959, 7, 454.

26. Gorlin, R., and S. G. Gorlin. Hydraulic formula for calculation of the area of the stenotic mitral valve, other cardiac valves, and central circulatory shunts. Amer. Heart J. 1951, 41, 1.

27. Rodrigo, F. A. Estimation of valve area and "valvular resistance." A critical study of the physical basis of the methods employed. Amer. Heart J. 1953, 45, 1.

28. Davis, P. K. B., and J. B. Kinmonth. The movements of the annulus of the mitral valve. J. cardiovasc. Surg. (Torino) 1963, 4, 427.

29. White, P. D. Cabot case 43111. New Engl. J. Med. 1957, 256, 516. 